\title{
Perkuatan Struktur Pilar Jembatan Akibat Mutu Beton yang Tidak Memenuhi Syarat
}

\author{
M. Sigit Darmawan \\ Program Diploma Teknik Sipil Institut Teknologi Sepuluh Nopember Surabaya \\ Email:msdarmawan@ce.its.ac.id
}

\begin{abstract}
Structural strengthening sometimes cannot be avoided when field condition deviates from the condition assumed in the design phase. For example, when the actual compressive strength achieved in the project is lower than the specified strength then the structure must be evaluated and reviewed. Two options are available for structure which does not comply with the specification, demolition or strengthening. In general, strengthening is preferred because this option is relatively cheap and does not affect project completion significantly. In this paper, structural strengthening of bridge pier is described and discussed. The method used is a combination between thickening of pier dimension and addition of main reinforcement. This method is opted as it can increase both flexural and normal capacity of bridge pier. From the analysis, it is found that the safety factor of bridge pier after strengthening increases up to $30 \%$ from its original safety factor. The additional reinforcement must be anchored properly at the bottom of bridge pier to fulfill its intended function and shear connector should be installed between new and old concrete to prevent slippage as assumed in the design of strengthening.
\end{abstract}

Keywords: structural strengthening, reinforcement, thickening, safety factor

Abstrak

Perkuatan struktur sering tidak dapat dihindari bila ada kondisi yang direncanakan tidak dapat dipenuhi. Salah satu masalah yang sering terjadi pada struktur beton bertulang adalah mutu beton yang direncanakan tidak memenuhi spesifikasi yang ditetapkan. Berdasarkan ketentuan yang ada struktur beton yang tidak memenuhi syarat dapat dibongkar atau diperkuat. Perkuatan sering menjadi pilihan karena menghemat biaya dan waktu pelaksanaan. Perkuatan yang dibahas pada tulisan ini adalah perkuatan pilar jembatan dengan mengkombinasikan antara penambahan dimensi pilar dan penambahan tulangan utama. Metoda ini dipilih karena dapat menaikkan baik kekuatan lentur maupun normal dari pilar jembatan. Dari hasil analisa didapatkan angka keamanan struktur perkuatan dapat dinaikkan hingga 30\% melebihi angka keamanan sesuai disain awal. Untuk menjamin agar tulangan dapat bekerja dengan baik perlu dilakukan pengangkeran tulangan tambahan pada ujung bawah pilar serta pemasangan penghubung geser agar beton lama dan baru dapat bekerja sesuai anggapan dalam perhitungan.

Kata kunci: perkuatan struktur, tulangan, penebalan, angka keamanan

\section{Pendahuluan}

Pada tahap pelaksanaan pekerjaan struktur beton kadang-kadang terjadi mutu beton yang direncanakan tidak memenuhi persyaratan yang telah ditetapkan. Tidak terpenuhinya mutu beton dapat disebabkan adanya perubahan kualitas material yang dipakai dan atau adanya kesalahan dalam proses penimbangan dan pencampuran beton. Bila kondisi ini sungguh-sungguh terjadi maka langkah-langkah yang dapat dilakukan sesuai SNI-2847-2013 (BSN 2013) adalah sebagai berikut:

Jurnal APLIKASI: Media Informasi \& Komunikasi Aplikasi Teknik Sipil Terkini Halaman 89 
- Struktur dibongkar dan diganti dengan struktur baru

- Dilakukan loading tes untuk menentukan kelayakan struktur

- Struktur dipertahankan dan diperkuat

Pembongkaran elemen struktur pada umumnya berusaha untuk dihindari karena pembongkaran dapat menyebabkan tambahan waktu pelaksanaan. Bila waktu pelaksanaan sangat terbatas pembongkaran bukan pilihan yang disukai. Loading tes juga jarang dilakukan karena tidak mudah pelaksanaannya, butuh waktu lama dan mahal biayanya. Apalagi pada saat loading tes ada resiko terjadi kegagalan struktur bila elemen struktur tidak mampu memikul beban yang direncanakan (Stewart dan Val 2003). Dengan demikian perkuatan struktur sering menjadi alternatif yang terbaik untuk menyelesaikan persoalan yang terjadi.

Pada tulisan ini akan dibahas salah satu metoda perkuatan yang dapat dipakai pada pilar jembatan bila mutu beton tidak memenuhi syarat. Perkuatan yang dimaksud disini adalah perkuatan dengan melakukan pembesaran dimensi pilar dan menambah tulangan utama.

\section{Metodologi}

Metoda perkuatan pada pilar jembatan akan dibahas dengan urutan sebagai berikut:

- Pemilihan metoda perkuatan

- Perhitungan struktur perkuatan

- Perbandingan kekuatan struktur perkuatan dan struktur sesuai disain awal

\section{- Kesimpulan}

Untuk memberi gambaran yang lebih jelas tentang metoda perkuatan pada pilar jembatan maka akan disajikan sebuah contoh perhitungan perkuatan akibat mutu beton $\left(\mathrm{f}_{\mathrm{c}}\right)$ sebesar $28 \mathrm{MPa}$ tidak tercapai. Dari hasil tes tekan benda uji core-drill didapatkan mutu beton terendah sebesar 20.4 MPa. Nilai mutu beton ini yang akan dipakai sebagai dasar perhitungan perkuatan pada pilar jembatan.

\section{Hasil dan Pembahasan}

\subsection{Pemilihan Metoda Perkuatan}

Sebelum memutuskan untuk memakai tipe perkuatan yang dipakai, maka perlu dilakukan perbandingan antara metoda perkuatan satu dengan yang lainnya. Faktor-faktor yang perlu diperhitungkan saat mendesain perkuatan tidak berbeda dengan prinsip dasar disain pada umumnya, yaitu

- Angka keamananan yang didapatkan tidak boleh lebih rendah dari angka keamanan sesuai peraturan/standar yang berlaku

- Umur perkuatan

- Waktu pelaksanaan

- Biaya yang diperlukan

Adapun metoda perkuatan yang dapat dipakai untuk pilar jembatan antara lain adalah

- Pembesaran dimensi elemen struktur (thickening/jacketting)

- Melakukan pengekangan (confinement)

- Penambahan tulangan utama

- Penggunaan Carbon Fiber Reinforcement 
- Kombinasi dari berbagai metoda yang ada

Dari hasil analisa awal maka pada akhirnya diputuskan memakai perkuatan dengan cara pembesaran dimensi dan penambahan tulangan utama. Cara ini dipilih karena lebih mudah pelaksanaanya dan biaya cukup murah bila dibandingkan cara yang lain. Metoda ini juga dipilih karena dapat menaikkan kapasitas pilar dalam menerima kombinasi lentur dan normal secara bersamaan. Perkuatan dengan cara pengekangan (confinement) atau penebalan dimensi tidak cukup efektif untuk perkuatan pilar karena hanya menaikkan kapasitas dalam memikul gaya normal saja (Tavio dkk 2012).

\subsection{Perhitungan Perkuatan}

Untuk memberi gambaran awal maka dilakukan analisa angka keamanan pilar jembatan sesuai disain awal. Untuk keperluan analisa perkuatan dipakai program bantu komputer yang dikeluarkan oleh Portland Cement
Association (PCA 2004). Adapun beban yang harus dipikul oleh pilar adalah sebagai berikut:

a) Akibat beban tetap

- $\mathrm{M}_{\mathrm{u}}=376$ ton-m (Lentur)

- $\mathrm{P}_{\mathrm{u}}=652$ ton (Normal)

- $\mathrm{D}_{\mathrm{u}}=55$ ton (Geser)

b) Akibat beban sementara

- $\mathrm{M}_{\mathrm{u}}=387$ ton- $\mathrm{m}$

- $\mathrm{P}_{\mathrm{u}}=510$ ton

- $\mathrm{D}_{\mathrm{u}}=61$ ton

Hasil perhitungan kekuatan pilar sesuai disain awal dengan tulangan utama 94D25 (persentasi tulangan sebesar $2.39 \%$ ) disajikan pada Gambar 1 dan 2 .

Gambar 1 menunjukkan pilar sesuai disain awal mempunyai dimensi $2500 \mathrm{x}$ $900 \mathrm{~mm}^{2}$. Gambar tersebut menunjukkan bahwa akibat beban tetap dan beban sementara, pilar dalam kondisi memenuhi persyaratan disain karena posisi beban dalam batas-batas kurva diagram interaksi.

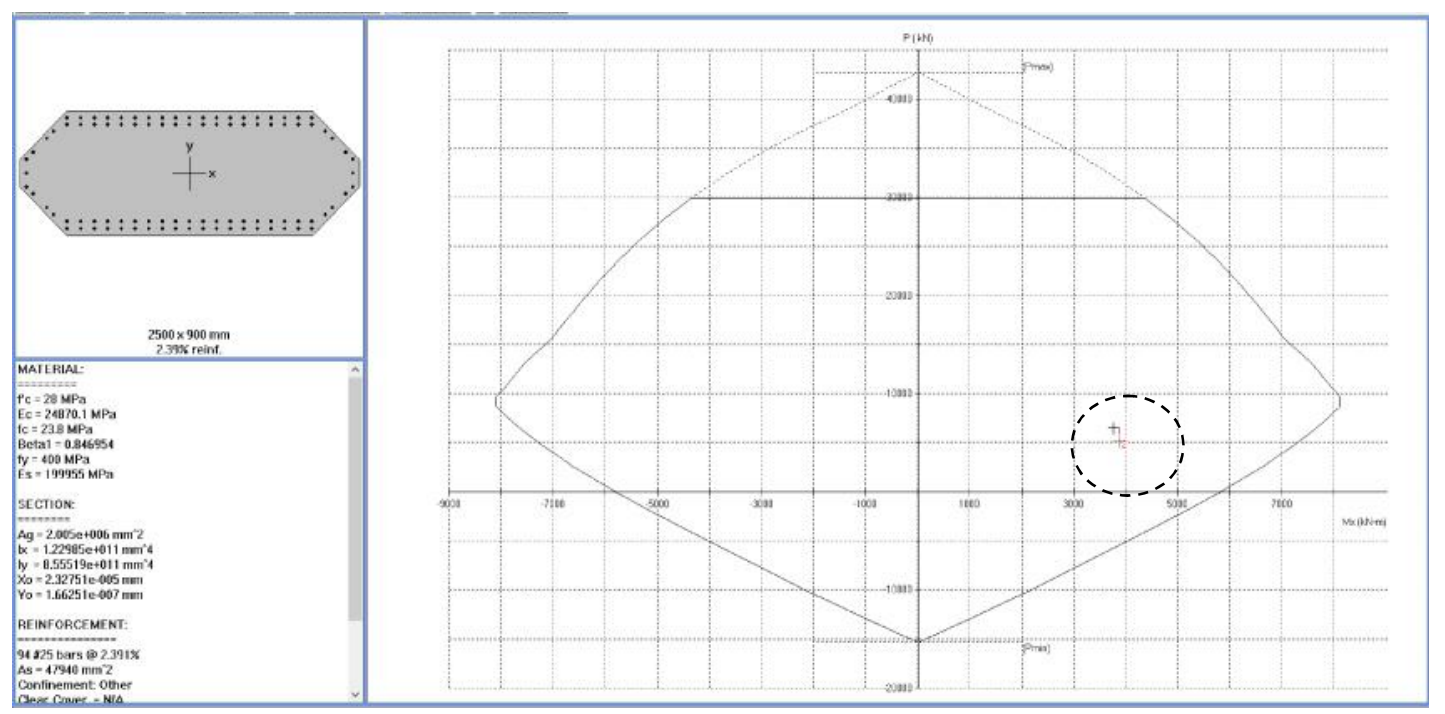

Gambar 1. Diagram Interaksi M-P Pilar Sesuai Disain Awal 


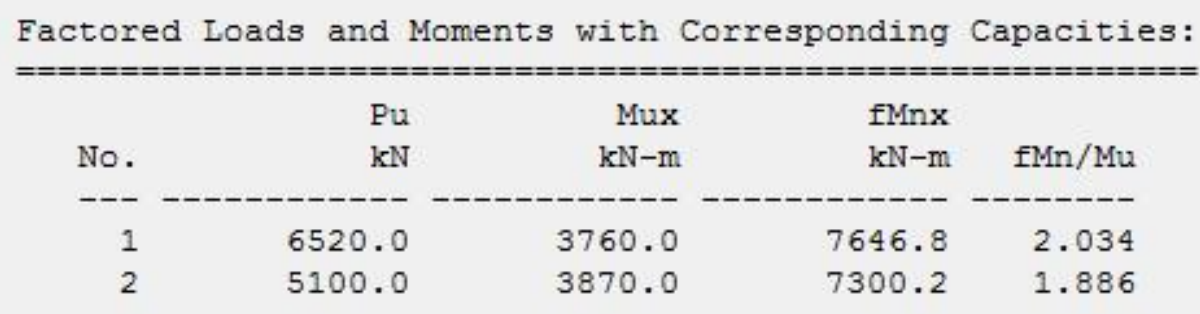

Gambar 2. Angka Keamanan Pilar Sesuai Disain Awal

Besarnya angka keamanan akibat beban tetap sebesar 2.034 dan beban sementara 1.886. Angka keamanan ini tercapai bila mutu betonnya ( $\mathrm{f}_{\mathrm{c}}$ ) sesuai dengan disain awal sebesar sebesar $28 \mathrm{MPa}$. Bila mutu beton hanya sebesar 20.4 MPa maka angka keamanannya tidak sebesar angka keamanan sesuai disain, yaitu hanya sebesar 1.942 untuk beban tetap dan 1.83 untuk beban sementara. Angka keamanan ini masih cukup besar tetapi masih lebih rendah bila dibandingkan dengan angka keamanan sesuai disain awal sehingga diperlukan adanya perkuatan.

Dari hasil evaluasi disain perkuatan dengan menambah ketebalan dimensi pilar sebesar $20 \mathrm{~cm}$, sesungguhnya telah dapat mengembalikan angka keamanan pilar sesuai disain awal. Namun demikian penebalan pilar saja tanpa diberi tulangan tambahan dikhawatirkan menimbulkan retak pada beton baru akibat pengaruh susut. Untuk itu dipasang tulangan tambahan yang difungsikan juga sebagai tulangan utama. Agar tulangan dapat berfungsi dengan baik maka perlu dilakukan penjangkaran pada beton lama (pile cap) dengan memakai angker kimia (chemical anchor). Penampang pilar setelah ditebalkan sebesar $20 \mathrm{~cm}$ dan ditambah tulangan 30D16 dapat dilihat pada
Gambar 3. Tulangan D16 dipakai sebagai perkuatan dan bukan tulangan D25 dengan tujuan agar diperoleh penghematan/efisiensi biaya.

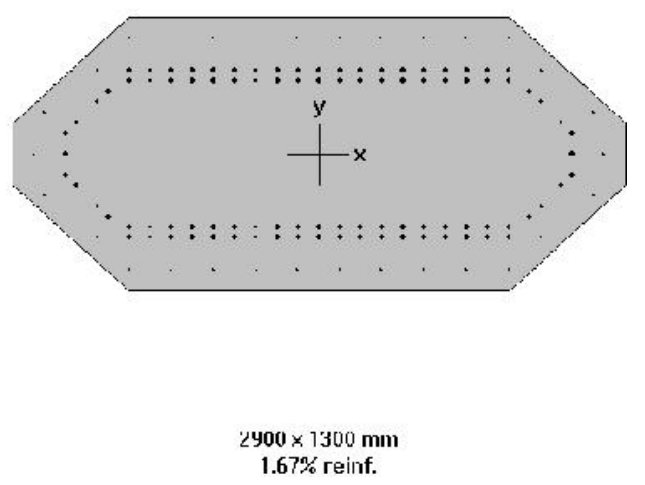

Gambar 3. Penampang Pilar dengan Penebalan $20 \mathrm{~cm}$ dan Tambahan Tulangan 30D16

Perlu dijelaskan disini bahwa karena ada perbedaan mutu beton lama dan beton baru maka dilakukan konversi luasan dengan memakai perbandingan modulus elastis beton sebesar 1.17. Hasil konversi penampang dapat dilihat pada Gambar 4. Gambar 4 menunjukkan bahwa akibat konversi mutu beton terjadi penambahan dimensi lateral penampang dari $2900 \mathrm{~mm}$ menjadi 3000 $\mathrm{mm}$ dan penurunan persentasi tulangan dari $1.67 \%$ menjadi $1.56 \%$. Persentasi tulangan pilar dengan penebalan masih jauh dibawah persentasi sesuai disain awal sebesar $2.39 \%$. 


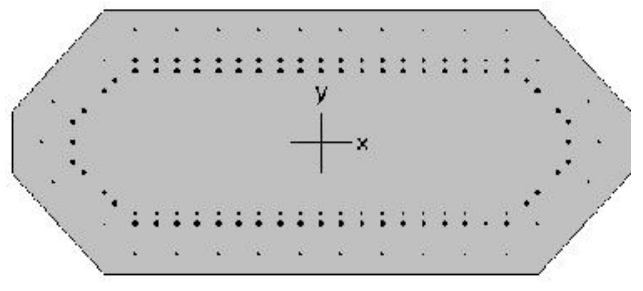

$3000 \times 1300$ mIIII $1.56 \%$ reinl.

Gambar 4. Penampang Pilar dengan Penebalan dan Tambahan Tulangan Setelah Konversi Mutu Beton

\subsection{Perbandingan Kekuatan}

Selanjutnya pada Gambar 5 dan 6 disajikan hasil evaluasi penampang dengan perkuatan.

Gambar 5 menunjukkan bahwa akibat beban tetap dan beban sementara pilar dengan perkuatan sudah dalam kondisi memenuhi persyaratan disain karena posisi beban dalam batas-batas kurva diagram interaksi. Besarnya angka keamanan akibat beban tetap sebesar 2.631 dan beban sementara 2.475. Hasil ini menunjukkan bahwa telah terjadi peningkatan angka keamanan sebesar $30 \%$ dari angka keamanan sesuai disain awal.

Untuk mendapatkan gambaran yang jelas antara kekuatan pilar sesuai disain awal dan pilar dengan perkuatan maka interaksi diagram kedua kolom disajikan pada Gambar 7. Gambar tersebut menunjukkan bahwa pilar dengan perkuatan mempunyai kekuatan yang lebih besar dibandingkan pilar sesuai disain awal. Batas-batas interaksi diagram pilar sesuai disain awal berada didalam kurva diagram interaksi pilar dengan perkuatan.

Selanjutnya untuk menjamin kerjasama beton lama dan baru perlu dilakukan pemasangan penghubung geser (shear connector). Perhitungan shear connector tidak dibahas secara mendetail disini dan dapat dilihat pada literatur yang ada (Popov 1990).

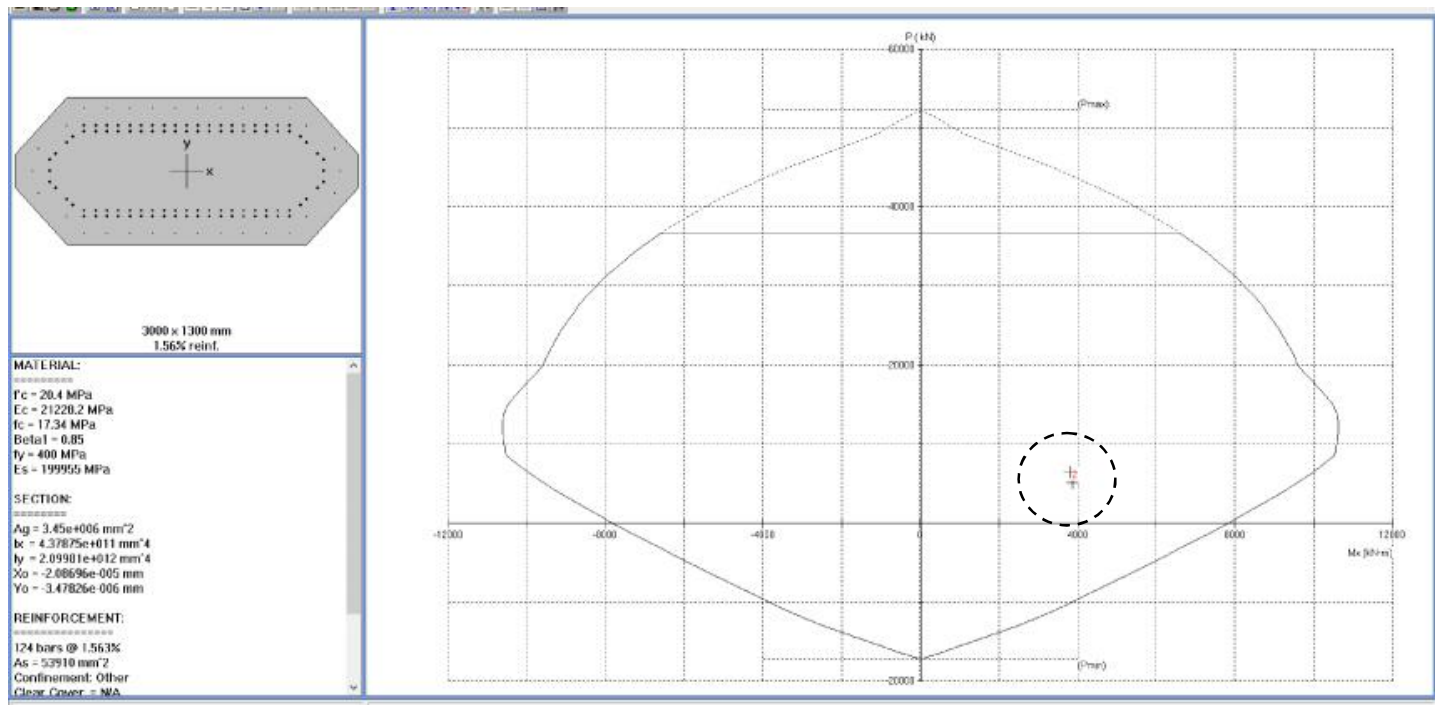

Gambar 5. Diagram Interaksi M-P Pilar dengan Perkuatan

Jurnal APLIKASI: Media Informasi \& Komunikasi Aplikasi Teknik Sipil Terkini Halaman 93 


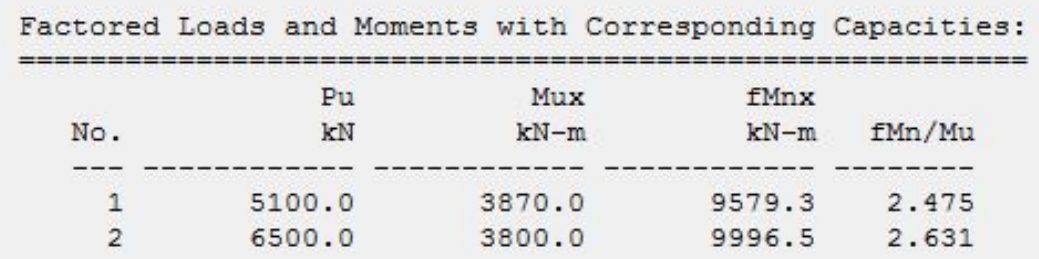

Gambar 6. Angka Keamanan Pilar dengan Perkuata

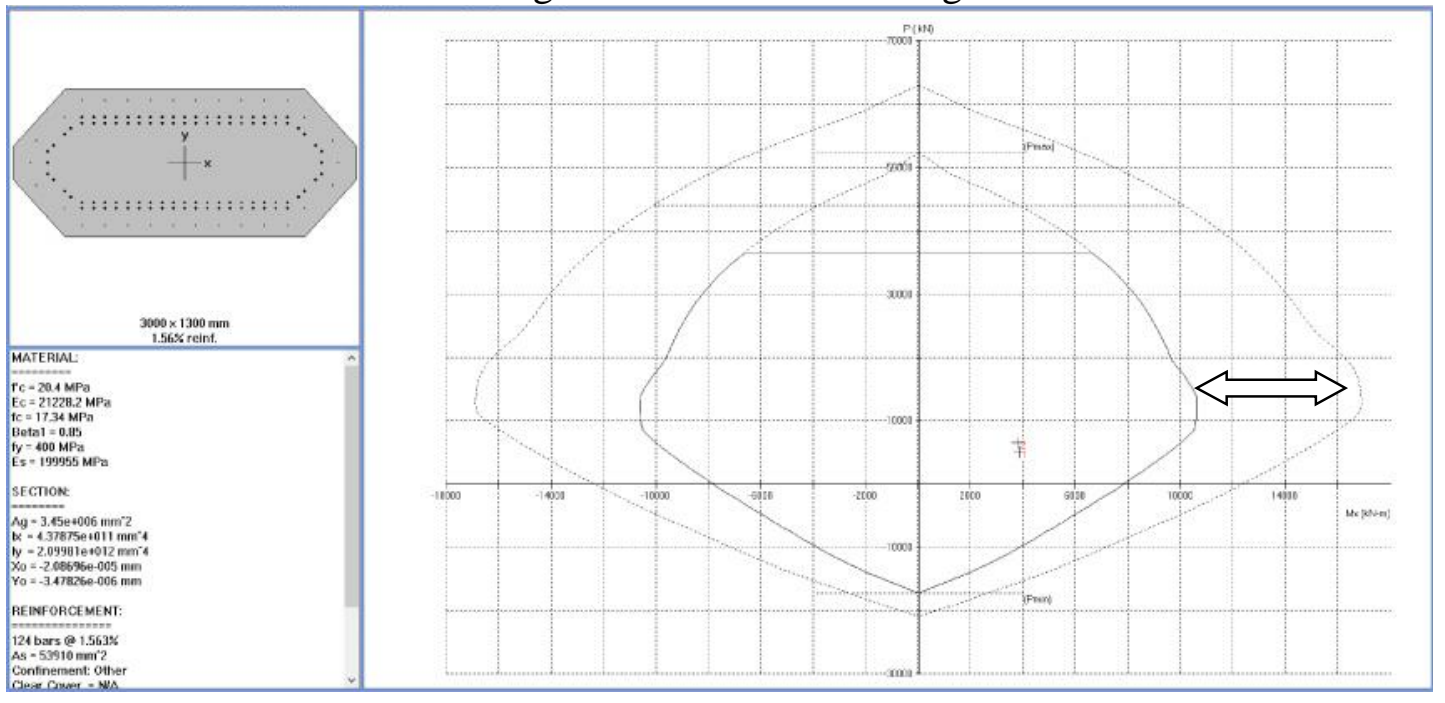

Gambar 7. Diagram Interaksi M-P Pilar dengan Perkuatan dan Pilar sesuai Disain Awal

Dari hasil perhitungan diperlukan shear connector D13 dengan jarak vertikal 60 cm sejumlah 15 buah pada 1 barisnya. Penghubung geser dipasang memakai angker kimia dari epoxy pada beton lama dan ditanam minimal sedalam 120 $\mathrm{mm}$. Hasil perhitungan disajikan pada Gambar 8.

\section{Simpulan}

Dari hasil perhitungan perkuatan pada pilar jembatan dengan penambahan dimensi $20 \mathrm{~cm}$ dan tulangan 30D16 didapatkan hasil sebagai berikut:

- Pilar dengan perkuatan mampu memikul beban sesuai disain awal,

- Dari hasil perhitungan didapatkan peningkatan angka keamanan sebesar 30\% dibandingkan dengan angka keamanan sesuai disain awal
- Angka keamanan terendah pilar semula 1.886 meningkat menjadi 2.475 ,

- Agar tulangan vertikal D16 dapat bekerja dengan baik maka perlu ditanam (diangker) minimal 250 mm pada kaki pondasi dengan memakai angker kimia (chemical anchor epoxy),

- Untuk menjamin kerjasama beton baru dan lama dipasang Penghubung geser (shear connector) D13 sebanyak 15 buah per baris pada 1 satu sisi dengan jarak $600 \mathrm{~mm}$. Penghubung geser dipasang memakai angker kimia dari epoxy pada beton lama dan ditanam minimal sedalam $120 \mathrm{~mm}$. 


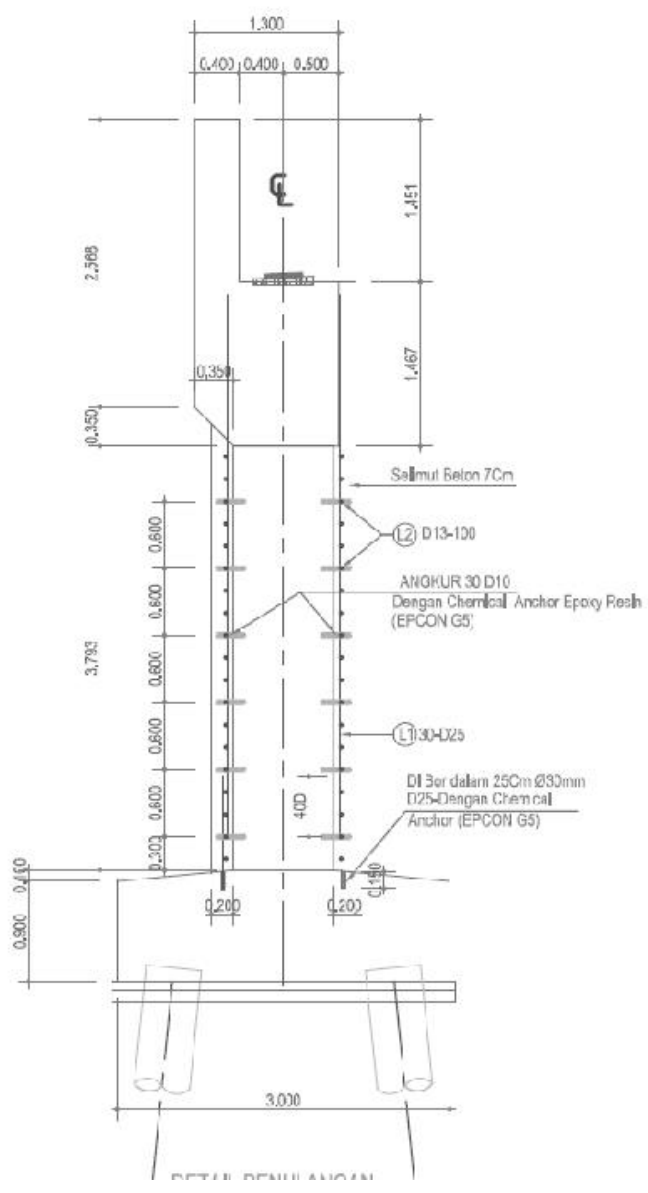

Gambar 8. Penempatan Shear Connector Pada Pilar

\section{Daftar Pustaka}

Egor P. Popov. (1990). Engineering Mechanics of Solid, Prentice-Hall International Series in Civil Engineering and Engineering Mechanics.

PCA Column Manual, Portland Cemen Association, USA, 2004.

Stewart, M. G. dan Val D. V., (2003). "Multiple Limit States and Expected Failure Costs for Deteriorating Reinforced Concrete Bridges", Journal of Bridge Engineering, ASCE, Vol. 8, No. 6, pp. 405-415.
Tata Cara Perencanaan Struktur Beton Untuk Bangunan Gedung-SNI2847, BSN, 2013.

Tavio, Kusuma, B. dan Suprobo P. (2012). " Experimental Behavior of Concrete Columns Confined by Welded Wire Fabric as Transverse Reinforcement under Axial Compression", ACI Structural Journal, Vol. 109, No. 3, pp. 339348. 
Halaman ini sengaja dikosongkan 